\title{
Why treating early, treating well, and treating for life is important in schizophrenia
}

Rene Kahn

\author{
From $1^{\text {st }}$ International Congress on Neurobiology and Clinical Psychopharmacology and European \\ Psychiatric Association Conference on Treatment Guidance \\ Thessaloniki, Greece. 19-22 November 2009
}

Schizophrenia is a progressive illness, with many psychotic episodes. Brain imaging studies have consistently demonstrated brain abnormalities in patients with schizophrenia. These changes are largely confined to decreases in gray matter volumes and enlargement of the lateral and third ventricles. To date schizophrenia has been considered to result from abnormalities in neurodevelopment, with brain changes to be static. However, schizophrenia has long been thought to be a progressive or a degenerative, not a developmental, disorder. Indeed, Kraepelin considered the progressive clinical deterioration to be the hallmark of the disorder, naming it dementia praecox to reflect this particular aspect. Lately, others have re-emphasized the importance of the decline in functioning in schizophrenia as a clue to its pathogenesis, suggesting that the brain abnormalities in schizophrenia could be expected to reflect this clinical progression. Indeed, we and others have reported brain abnormalities to increase over time in schizophrenia. Interestingly, not all patients show changes in brain volumes over time: we demonstrated that the changes are particularly pronounced in those patients with a poor prognosis in the first years of illness. Moreover progressive changes are most pronounced in the frontal and temporal areas as postulated by Kraepelin over a hundred years ago. Interestingly, white matter did not change over time. Also we found that brain loss over time was most pronounced in patients who had been psychotic longest. Finally, the progression in these frontal brain changes appeared to be attenuated by treatment with atypical, but not by typical antipsychotics. Thus, not only are brain changes progressive in schizophrenia, they are clinically relevant since they are related to outcome and may be reversed

Department of Psychiatry and Head of the Division of Neuroscience at the University Medical Center, Utrecht, The Netherlands

BH. Med Central @ 2009 Kahn; licensee BioMed Central Ltd. by some of the atypical antipsychotics. With the evidence pointing to a link between progressive disease and patient outcomes, it is becoming increasingly clear that every effort should be made to prevent psychotic relapses. Using medications with maximal effect is therefore warranted.

Published: 22 April 2010

doi:10.1186/1744-859X-9-S1-S67

Cite this article as: Kahn: Why treating early, treating well, and treating for life is important in schizophrenia. Annals of General Psychiatry 2010 9(Suppl 1):S67.
Submit your next manuscript to BioMed Central and take full advantage of:

- Convenient online submission

- Thorough peer review

- No space constraints or color figure charges

- Immediate publication on acceptance

- Inclusion in PubMed, CAS, Scopus and Google Scholar

- Research which is freely available for redistribution

Submit your manuscript at www.biomedcentral.com/submit
C Biomed Central 